\title{
Synthesis and Investigation of Submicrometer Spherical Indium Oxide Particles
}

\author{
Sung-En Lin and Wen-Cheng J. Wei ${ }^{\dagger}$ \\ Department of Material Science and Engineering, National Taiwan University Taipei, Taiwan 106, ROC
}

\begin{abstract}
Spherical indium (In) oxide in submicrometer size is considered as a practical material in photonic bandgap applications. To obtain narrow size distribution, systematic studies of different conditions such as precursor concentration, reaction temperature, and other parameters have been carried out and are reported here. Tri- or dicarboxylic acid of citric acid (CA), malic acid, and tartaric acid were introduced into the reaction system and In-precipitates of spherical shape were produced. The particle size and internal morphology were observed by scanning electron microscopy and transmission electron microscopy. $\mathrm{X}$-ray diffraction and thermal analysis were performed. The reaction kinetics analysis shows that the reaction rate depends on the reaction temperature, urea, and In concentration rather than on CA.
\end{abstract}

\section{Introduction}

$\mathrm{T}$ fabricate a three-dimensional photonic bandgap (PBG) crystal, mono-dispersed particles with spherical shape and narrow size distribution are necessary. The term "monodispersed" is used to describe particles in systems with identical dispersive conditions. ${ }^{1}$ Mono-dispersed particles can be found in nature, such as haze, opal, and some other minerals. ${ }^{2,3}$ Based on different physical and chemical assembly routes, several techniques have been developed to produce "mono-dispersed" colloids. However, it is still difficult to synthesize the monodispersed particles or polydispersity by $<5 \%$ with spherical shape and submicrometer size. Further, agglomeration should be prevented for assembling the PBG crystal.

The Stöber ${ }^{4}$ method is most famous for the synthesis of mono-dispersed $\mathrm{SiO}_{2}$ spherical particles. Several experimental parameters, such as reaction temperature $\left(5^{\circ}-80^{\circ} \mathrm{C}\right)^{5}$ and ratios between the precursors, have used tried to control and explain the mechanisms.

Besides $\mathrm{SiO}_{2}, \mathrm{Y}_{2} \mathrm{O}_{3}$ spherical phosphor doped with $\mathrm{Tb}^{3+}, 6$ $\mathrm{CeO}_{2}$ spheres, ${ }^{2} \mathrm{ZnS}$ spheres, ${ }^{2} \mathrm{CdSe}$ spheres, ${ }^{2} \mathrm{CdCO}_{3}$ spheres, ${ }^{2}$ Al-hydrous oxide spheres, ${ }^{3}$ Cr-hydrous oxide spheres, ${ }^{3} \mathrm{MnPO}_{4}$ spheres, ${ }^{3} \mathrm{ZrO}_{2}$ spheres, ${ }^{7} \mathrm{ZnO}$ colloidal spheres, ${ }^{8}$ and $\mathrm{TiO}_{2}$ spheres ${ }^{9,10}$ have been synthesized.

Indium oxide $\left(\operatorname{In}_{2} \mathrm{O}_{3}\right)$ and its compound, especially for indium tin oxide, have recently received great attention from material scientists. $\mathrm{In}_{2} \mathrm{O}_{3}$, an $n$-type semiconductor with a wide bandgap of about $3.6 \mathrm{eV},{ }^{11}$ has been used for optoelectronic devices because of its photoluminescence properties. ${ }^{11}$ Along with its optical properties, $\mathrm{In}_{2} \mathrm{O}_{3}$ has also been used as a gas sensor, for $\mathrm{NO}_{2},{ }^{12} \mathrm{O}_{3},{ }^{13} \mathrm{CO},{ }^{13} \mathrm{NH}_{3},{ }^{14}$ or $\mathrm{H}_{2} .{ }^{15}$

Different shapes of $\operatorname{In}_{2} \mathrm{O}_{3}$ or $\mathrm{In}(\mathrm{OH})_{3}$ can be produced by different synthesis processes such as nanofibers or

M. Niederberger - contributing editor

Manuscript No. 23576. Received August 9, 2007; approved November 26, 2007. The work was financially supported by the National Science Council, under grant no. NSC95-2120-M002-001.

Author to whom correspondence should be addressed. e-mail: wjwei@ntu.edu.tw nanowires ${ }^{13,16-19}$ needle-like particles, ${ }^{20}$ cubes, ${ }^{13,16,21}$ rod-like particles, ${ }^{16,22}$ oval-shaped particles, ${ }^{23}$ or spherical particles. ${ }^{16,24}$

To assemble an ideal PBG crystal, the particles should be spherical, mono-sized in submicrometer scale, and in controlled dielectric constant. Although Yura et al. ${ }^{16}$ and Hamada et al. ${ }^{24}$ claimed that spherical particles could be synthesized by using the processes reported by them, the particles were not spherical and some fine feature (or subunits) can be observed in the reported micrographs.

In this study, we tried to synthesize spherical, mono-sized $\mathrm{In}_{2} \mathrm{O}_{3}$ by the sol-precipitation method for the applications of PBG crystal and study its formation kinetics. Adding $\alpha$-hydroxyl acids (AHAs) such as citric acid (CA), tartaric acid (TA), and malic acid (MA) was found to change the shape of the In-precipitates from anisotropic to spherical in this study. CA, TA, and MA are carboxylic acids, and their acidity comes from the carboxyl groups $(\mathrm{COOH})$. Each acid can sequentially release protons into the solution.

\section{Experimental Procedure}

Indium nitrate $\left(\mathrm{In}\left(\mathrm{NO}_{3}\right)_{3}\right)(99.9 \%$, Titanex Corp., Taoyuan, Taiwan, $\left.M_{\mathrm{W}}=318.83(\mathrm{~g} / \mathrm{mol})\right)$ was the starting material in this study. Urea $\left(\mathrm{CH}_{4} \mathrm{~N}_{2} \mathrm{O}, 99.5 \%\right.$, Acros, Morris Plains, NJ) was used to adjust the $\mathrm{pH}$ when the diluted nitrate solution was heated to temperatures higher than $65^{\circ} \mathrm{C}$. $\mathrm{CA}\left(\mathrm{C}_{6} \mathrm{H}_{8} \mathrm{O}_{4}\right.$, reagent grade, Acros), MA $\left(\mathrm{C}_{4} \mathrm{H}_{6} \mathrm{O}_{5}\right.$, reagent grade, Acros), and TA $\left(\mathrm{C}_{4} \mathrm{H}_{6} \mathrm{O}_{6}\right.$, reagent grade, Acros) were used. Specific ratios of $\mathrm{In}\left(\mathrm{NO}_{3}\right)_{3}$ solution, $\mathrm{CA}$, and urea were mixed as precursors and reacted at $75^{\circ}-90^{\circ} \mathrm{C}$ for $3-24 \mathrm{~h}$ to form a white spherical precipitate. MA and TA were used as the comparison cases. From several preliminary tests, it was found that the concentration of $\left[\operatorname{In}^{3+}\right]:[\mathrm{CA}]:[$ urea] $=2: 1: 15$ can be taken as the basic condition for generating a well-dispersed sphere.

Before further analysis, the precipitates after washing were dried at $105^{\circ} \mathrm{C}$ for at least $30 \mathrm{~min}$. The particle size and morphology were studied by field emission scanning electron microscopy (FESEM-1530, LEO Instrument, Cambridge, U.K.). The particles were dispersed in deionized water, and then dropped on a carbon film or silicon wafer. After drying the solution, the sample was coated with carbon or Pt to improve the electric conductivity of the sample. The particle size was statistically measured from at least 150 particles. For indepth study, a transmission electron microscope (TEM 100 CXII, JEOL Co., Tokyo, Japan) was used. The powder sample was placed in a Pt crucible and tested using thermogravimetric analysis (TGA) and differential thermal analysis (DTA) (Thermal Gravity Analyst 2000, Dupont Co., Wilmington, DE) systems. The crystalline phase was identified by an X-ray diffractometer (XRD, Philips PW 1972, Philips Instrument, Eindhoven, the Netherlands) using $\mathrm{Cu} K \alpha$ radiation. The applied voltage and current of the XRD were set at $30 \mathrm{kV}$ and $20 \mathrm{~mA}$, respectively. The scan speed was $3 \%$ min. The $\mathrm{pH}$ value of the solution was measured by a $\mathrm{pH}$ meter (SP-7, Digital $\mathrm{pH}$ Meter, Suntex, Taipei, Taiwan). Reaction kinetics with different $\mathrm{CA}$ additions were determined by monitoring the residual $\mathrm{In}^{3+}$ in solution by ICP-OES (JOBIN YVON Ultima2000, Longjumeau, France). 


\section{Results}

\section{(1) Effect of CA Addition and Reaction Temperature}

The concentration of CA was adjusted from $0.1 \times 10^{-2} \mathrm{~m}(\mathrm{~mol} /$ $\mathrm{kg}$ ) to $2.0 \times 10^{-2} \mathrm{~m}$ to study the effect of CA concentration as listed in Table I. For A-1 formulation, no precipitation occurred until $24 \mathrm{~h}$ at $90^{\circ} \mathrm{C}$. Once the concentration of CA increased to $0.5 \times 10^{-2} \mathrm{~m}$ (i.e., A-2), spherical particles were generated in $<3 \mathrm{~h}$. However, slight agglomeration was noted when the concentration of CA was $>1.0 \times 10^{-2} \mathrm{~m}$ (i.e., A-4 and A-5), as shown in Fig. 1. The size distribution became wider as more CA was used. The mean particle size of the precipitates versus the concentration of CA is plotted in Fig. 2. A linear relationship between the mean particle size and the concentration of CA is noted. The average particles size of In-precipitates can be manipulated by modifying the concentration of CA.

To investigate the internal structure of the particles, one of the samples (A-3) was calcined at $800^{\circ} \mathrm{C}$ for $1 \mathrm{~h}$ and then milled by ion milling. Typical images of bright field (BF) and center dark field (CDF) with diffraction pattern (DP) by TEM are shown in Fig. 3. Before calcination, In-precipitates displayed an amorphous phase (the XRD patterns would be shown later) and transformed to crystalline phase after heat treatment higher than about $400^{\circ} \mathrm{C}$. The $\mathrm{BF}$ cross-section image (Fig. 3 (a)) shows that the structure of the particles has a hollow core after calcination. The DP shown in Fig. 3(b) reveals that the
Table I. Formulation and Synthesis Conditions of the Particle Synthesized with Different Citric Acid Addition

\begin{tabular}{lccccr}
\hline Sample name & $\mathrm{In}^{3+}$ & Citric acid & Urea & Temperature $\left({ }^{\circ} \mathrm{C}\right)$ & Time (h) \\
\hline A-1 & 2 & 0.1 & 15 & 90 & 24 \\
A-2 & 2 & 0.5 & 15 & 90 & 3 \\
A-3 & 2 & 1.0 & 15 & 90 & 3 \\
A-4 & 2 & 1.5 & 15 & 90 & 3 \\
A-5 & 2 & 2.0 & 15 & 90 & 3 \\
B-0 & 2 & 0 & 15 & 80 & 7 \\
B-1 & 2 & 0.1 & 15 & 80 & 7,24 \\
B-2 & 2 & 0.3 & 15 & 80 & 7 \\
B-3 & 2 & 0.5 & 15 & 80 & 7 \\
B-4 & 2 & 1.0 & 15 & 80 & 7 \\
B-5 & 2 & 1.5 & 15 & 80 & 7 \\
\hline
\end{tabular}

The unit of the concentration is $10^{-2} \mathrm{~mol} / \mathrm{kg}$

structure is polycrystalline $\operatorname{In}_{2} \mathrm{O}_{3}$ phase. Twenty to $50 \mathrm{~nm}$ crystal size can be observed from CDF, as shown in Fig. 3(c).

From the results of the reaction at $90^{\circ} \mathrm{C}$, two disadvantages, large size distribution and agglomeration, should be prevented for the applications. Therefore, the reaction temperature was decreased to $80^{\circ}$ and $75^{\circ} \mathrm{C}$ to decrease the reaction rate and to manipulate the precipitation condition. (a)

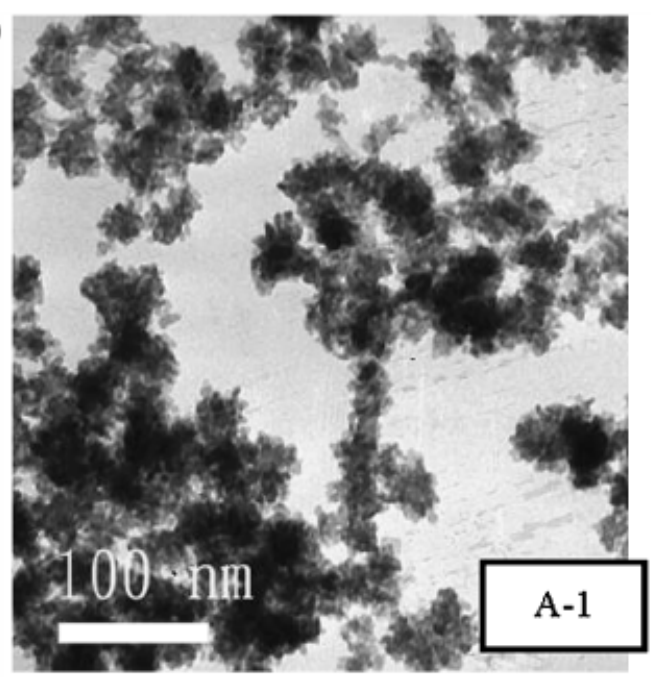

(c)

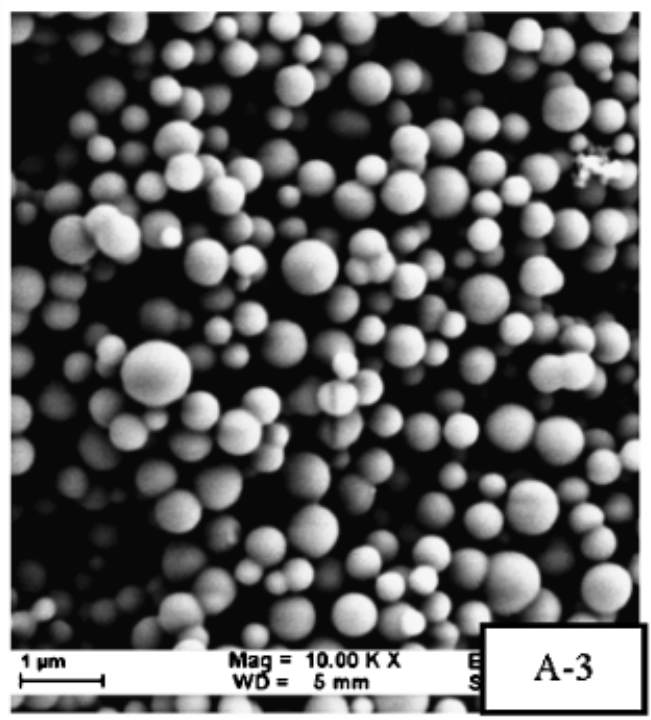

(b)

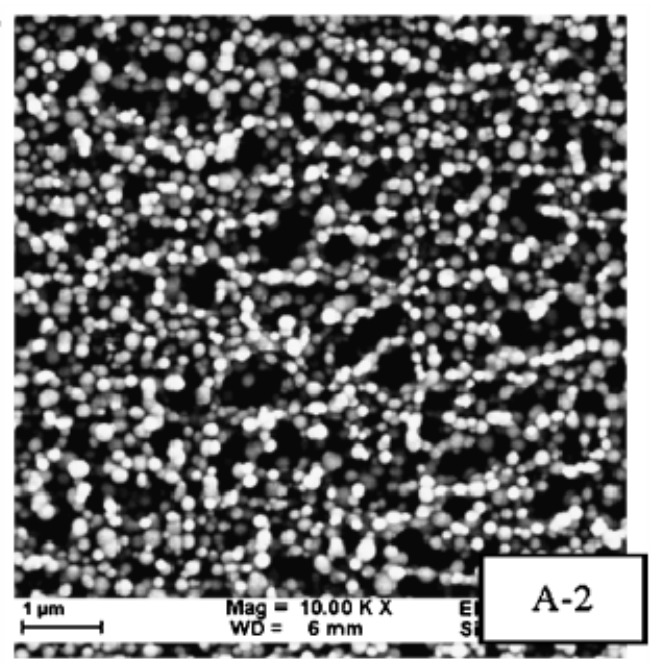

(d)

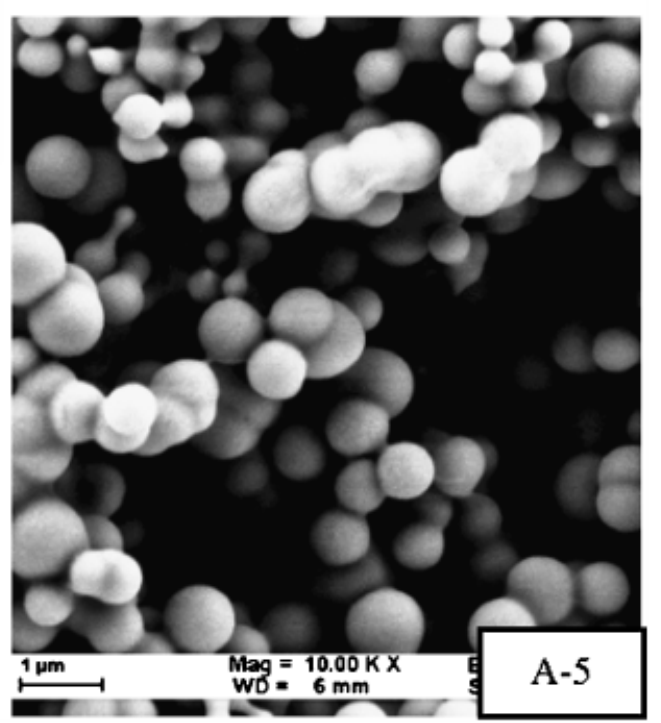

Fig. 1. Scanning electron microscopic and transmission electron microscopic micrographs of precipitates with different citric acid (CA) additions

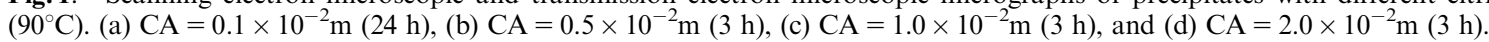




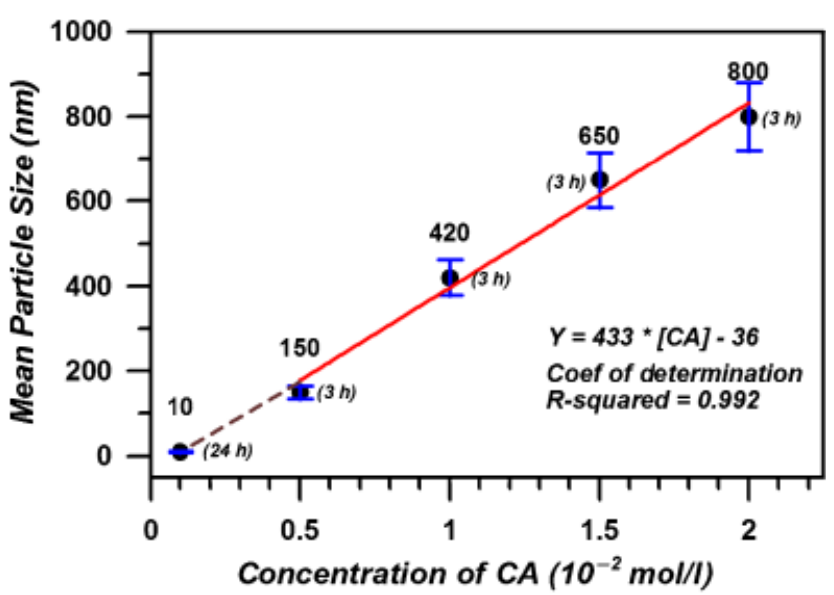

Fig. 2. Effect of citric acid concentration on the particle size of A-series samples aging at $90^{\circ} \mathrm{C}$ for $3 \mathrm{~h}$.

B-0 sample (without CA addition) shows stick-like precipitates, which is similar to our previous results. ${ }^{22}$ Besides, when the ratio of $[\mathrm{CA}] /\left[\mathrm{In}^{3+}\right]$ in B-series samples was equal to or higher than 0.5 , some agglomeration or dumbbell structure was seen. At $80^{\circ} \mathrm{C}$, the solution produced precipitates in $<7 \mathrm{~h}$. However, if a little CA, i.e., B-1 with $0.1 \times 10^{-2} \mathrm{~m} \mathrm{CA}$, was added, no precipitates could be obtained until more than $10 \mathrm{~h}$.

The SEM results show that the more the CA used, the larger the particle size. The TEM result of the B-1 case revealed that the precipitates are amorphous and form a cluster, as sample A-1. Each cluster was $<50 \mathrm{~nm}$. A linear relationship between particle size and concentration of CA can be obtained, which exhibits results similar to the cases aged at $90^{\circ} \mathrm{C}$ (Fig. 4). Besides, the size distribution and dispersive conditions at $80^{\circ} \mathrm{C}$ were obviously improved.

\section{(2) Reaction Kinetics for Different Concentrations}

For further examination, reaction kinetics were analyzed by ICP. Here, we set the ratio of $\left[\operatorname{In}^{3+}\right]:[\mathrm{CA}]:[$ urea $]=2: 1: 15$ as the standard (STD) condition. Then, the concentration of STD was decreased proportionally as listed in Table II. For the C-series, the linear relationship was characteristic of a zero-order reaction and the reaction rates for C-1(A-3)-C-4 decreased from 9.2 to 2 $\mathrm{ppm} / \mathrm{min}$, as shown in Fig. 5(a). This means that a lower initial concentration would result in a slower reaction rate. It may be caused by the lower concentration of $\left[\mathrm{In}^{3+}\right]$ or [CA] or [urea], or all of them. At $90^{\circ} \mathrm{C}$, almost all the $\left[\operatorname{In}^{3+}\right]$ was used up for all the (a)

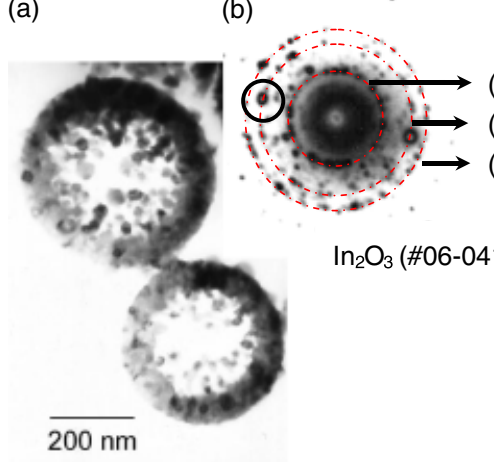

(c)

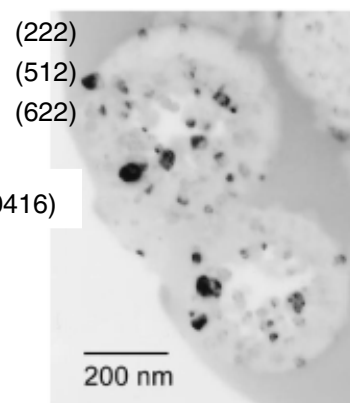

Fig. 3. Transmission electron microscopy cross-sectional micrographs of the sample (A-3) after calcination at $800^{\circ} \mathrm{C} / \mathrm{h}\left(10^{\circ} \mathrm{C} / \mathrm{min}\right)$. (a) Bright field image of the sample and (b) diffraction pattern being indexed according to the $\mathrm{In}_{2} \mathrm{O}_{3}$ phase (JCPD file \#06-0416). (c) Center dark field negative image (the same position with (a)). The hollow core and solid shell can be observed.

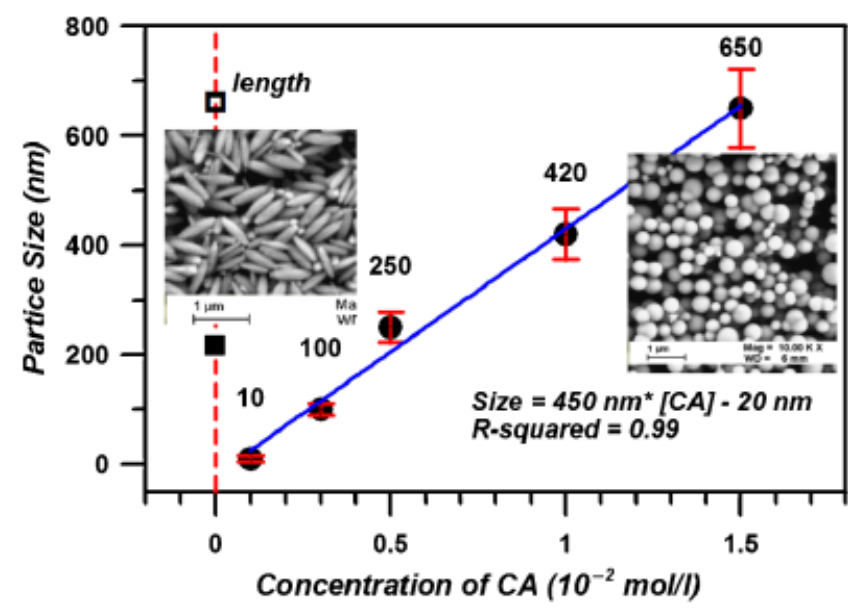

Fig. 4. Average particle size plotted against citric acid concentration. Aging temperature was $80^{\circ} \mathrm{C}$ for $7 \mathrm{~h}$.

cases before being aged for $6 \mathrm{~h}$. Similar results could be seen in the D-series, as shown in Fig. 5(b). The reaction rates decreased from 1.38 to $0.31 \mathrm{ppm} / \mathrm{min}$. Thirty hours are necessary to use up the contents of $\left[\operatorname{In}^{3+}\right]$ for the D-series aged at $75^{\circ} \mathrm{C}$.

To examine the effect of $\mathrm{CA}$ on reaction rate, the residual $\left[\mathrm{In}^{3+}\right]$ during reaction for B-0, B-2, and B-4 was monitored by ICP. As shown in Fig. 6, the fitting curve revealed the reaction rates for those three cases as equal, about $2.0 \mathrm{ppm} / \mathrm{min}$, which means the reaction rate was not influenced by the addition of CA.

The activation energy $Q$ of the reaction in cases with different initial concentration, revealing the dependence on temperature, was calculated by the Arrhenius equation. The reaction rate $R(T)$ varied as a function of the reciprocal absolute temperature, i.e.,

$$
R(T)=R_{0} \exp \left(-Q / R_{\mathrm{gas}} T\right)
$$

where $R_{0}$ is the frequency factor or preexponential factor, $R_{\mathrm{gas}}$ is the gas constant, which is equal to $8.314 \mathrm{~J} \cdot(\mathrm{mol} \cdot K)^{-1}$, and $T$ is in absolute or Kelvin units.

An Arrhenius plot of reaction rates versus reciprocal absolute temperature for three cases (STD, 50\% STD, and 25\% STD condition) is shown in Fig. 7. The activation energies for the three cases are $-139.7,-123.9$, and $-130 \mathrm{~kJ} / \mathrm{mol}$, respectively.

\section{(3) Synthesis and Analysis of Mono-dispersive In-Precipitate Particles}

The SEM image was shown for sample D-3; particles in well-dispersed and narrow size distribution were obtained when aged at $75^{\circ} \mathrm{C}$ for $5 \mathrm{~h}$ (Fig. 8(a)). When aged for a longer period, i.e., $16 \mathrm{~h}$, better size distribution can be observed as shown in Fig. 8(b). The average size increased from 390 to $420 \mathrm{~nm}$, and the standard deviation decreased from about 60 to 50 when aged from 5 to $16 \mathrm{~h}$.

Table II. Formulation and Synthesis Conditions of the Particle Synthesized with Different STD Ratios

\begin{tabular}{llllcc}
\hline $\begin{array}{l}\text { Sample } \\
\text { name }\end{array}$ & $\mathrm{In}^{3+}$ & $\begin{array}{c}\text { Citric } \\
\text { acid }\end{array}$ & Urea & $\begin{array}{c}\text { Temperature } \\
\left({ }^{\circ} \mathrm{C}\right)\end{array}$ & $\begin{array}{c}\text { Time } \\
(\mathrm{h})\end{array}$ \\
\hline C-1 (A-3) & 2 & 1 & 15 & 90 & $1-12$ \\
C-2 & 1.5 & 0.75 & 15 & 90 & $1-12$ \\
C-3 & 1 & 0.50 & 15 & 90 & $1-12$ \\
C-4 & 0.5 & 1.5 & 15 & 90 & $1-12$ \\
D-1 & 2 & 1 & 15 & 75 & $1-36$ \\
D-2 & 1 & 0.5 & 7.5 & 75 & $1-36$ \\
D-3 & 0.5 & 0.25 & 3.75 & 75 & $1-36$ \\
\hline
\end{tabular}

The unit of the concentration is $10^{-2} \mathrm{~mol} / \mathrm{kg}$. 

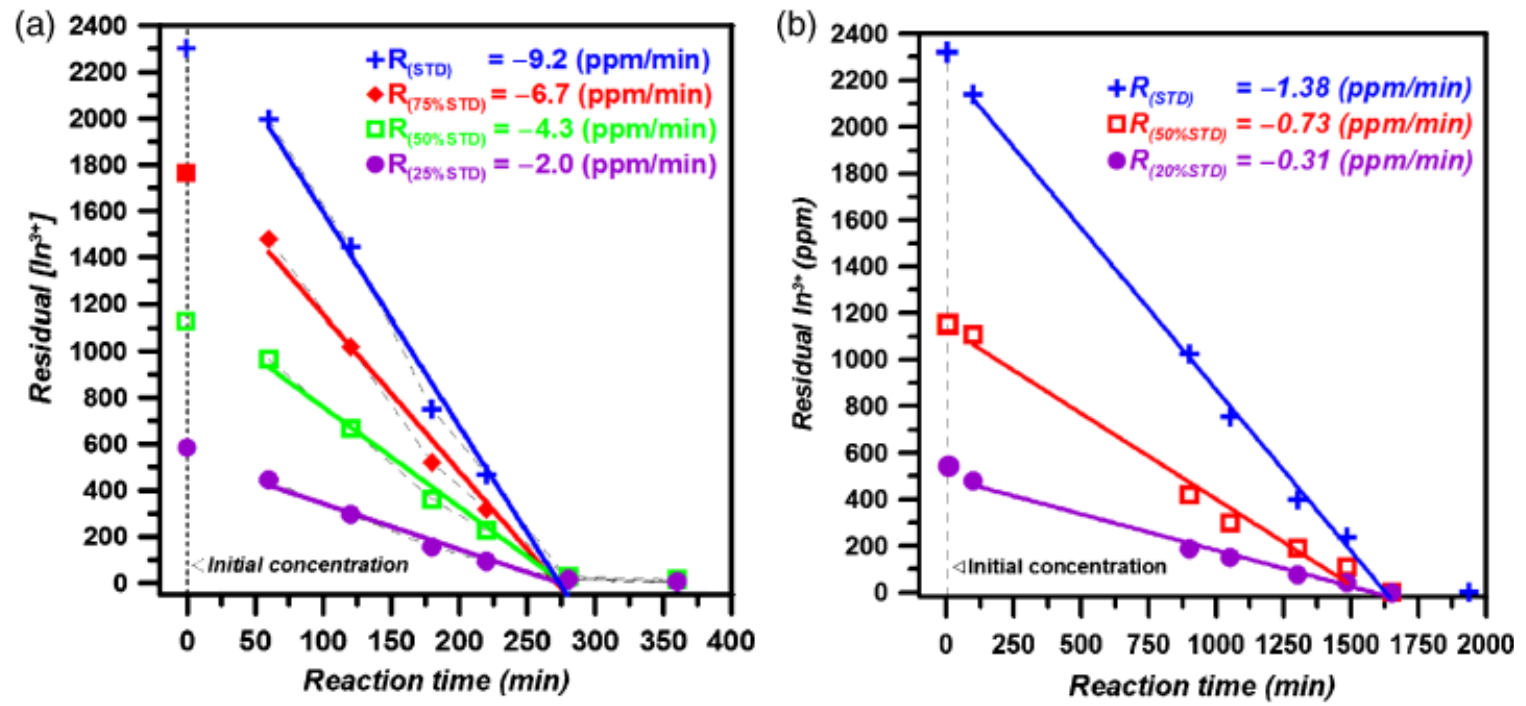

Fig. 5. Residual $\left[\mathrm{In}^{3+}\right]$ in solutions for different percentages of standard aged at (a) $90^{\circ} \mathrm{C}$ and (b) $75^{\circ} \mathrm{C}$.

TGA and DTA results of D-3 aged for $16 \mathrm{~h}$ are shown in Fig. 9. Major mass loss started from about $300^{\circ} \mathrm{C}$ and ended at $360^{\circ} \mathrm{C}$. No obvious exothermic or endothermic peak was noted below $300^{\circ} \mathrm{C}$. However, a large exothermic peak started at about $350^{\circ} \mathrm{C}$. Compared with sample B- 0 , which is the crystalline In $(\mathrm{OH})_{3}$ phase, the DTA result (Fig. 9, dotted line) reveals an endothermic peak before $300^{\circ} \mathrm{C}$ because of the dehydration reaction.

XRD patterns (Fig. 10) for sample D-3 are amorphous. For sample B-0 (without adding CA), the crystalline phase is $\mathrm{In}(\mathrm{OH})_{3}$. After calcination at $500^{\circ} \mathrm{C} / \mathrm{h}$, sample D-3 transforms into $\mathrm{In}_{2} \mathrm{O}_{3}$ phase.

Figure 11 shows the result of the Fourier transform infrared (FTIR) analysis of sample D-3 (aged for $16 \mathrm{~h}$ ). The sample was dried at $80^{\circ} \mathrm{C}$ for 3 days. As shown by Taguchi et al.'s report ${ }^{25}$ (synthesis of $\mathrm{LaMnO}_{3+\delta}$ with CA), the carboxylate anion resulted in absorption peaks at $1550-1650$ and $1400 \mathrm{~cm}^{-1}$ for strong asymmetric stretching and weak symmetric stretching, respectively. The other peaks resulting from the $\mathrm{In}-\mathrm{O}$ and In-OH bands were observed in the spectrum. ${ }^{26}$

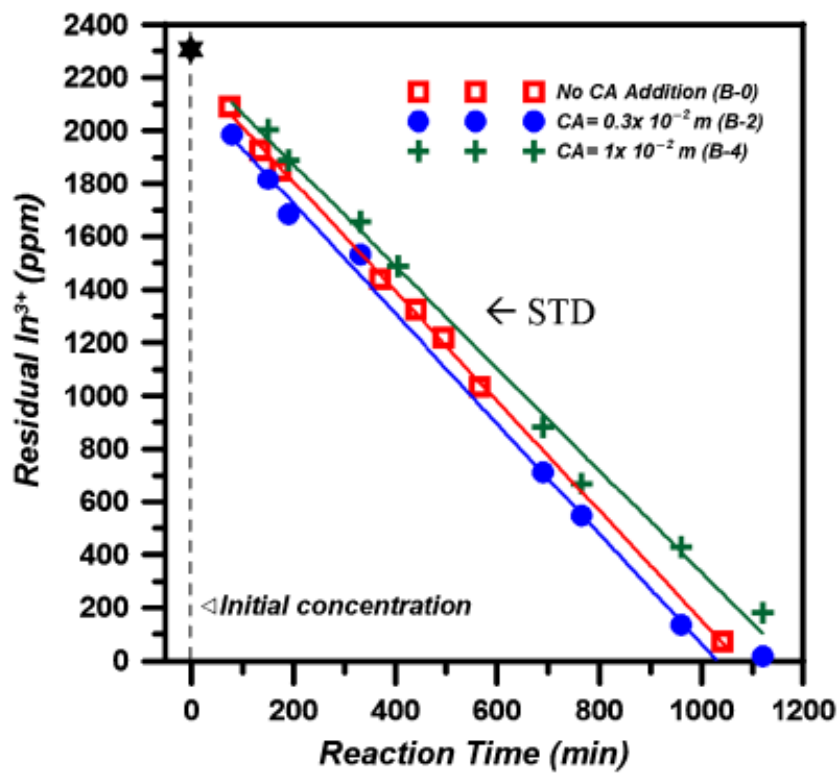

Fig. 6. Residual $\left[\mathrm{In}^{3+}\right]$ in solutions for different amounts of citric acid (CA) addition aged at $80^{\circ} \mathrm{C}$. The reaction rates for the three different cases are nearly equal to $-2 \mathrm{ppm} / \mathrm{min}$, even for the case with $\mathrm{CA}$ addition.

\section{(4) Effect of $\boldsymbol{T A}$ and $\boldsymbol{M A}$}

Besides CA, TA and MA are also a part of AHAs and are a sort of carboxylic acid with the carboxyl group $\mathrm{COOH}$ in their structure. CA is a tri-carboxylic acid, and TA and MA are dicarboxylic acids. Thus, they should perform similar functions. Table III listed the experimental conditions for the comparison of CA, TA, and MA with different concentrations. Figure 12 shows the SEM images of precipitates for the cases listed in Table III. All the samples were aged at $80^{\circ} \mathrm{C}$ for $6 \mathrm{~h}$. As anticipated, the cases with added TA and MA resulted in spherical precipitates, with size increasing with increasing amounts of the acids.

\section{Discussion}

From the results of the A-series as shown in Fig. 1, the sizes of particles were noticeably influenced by the amount of CA.

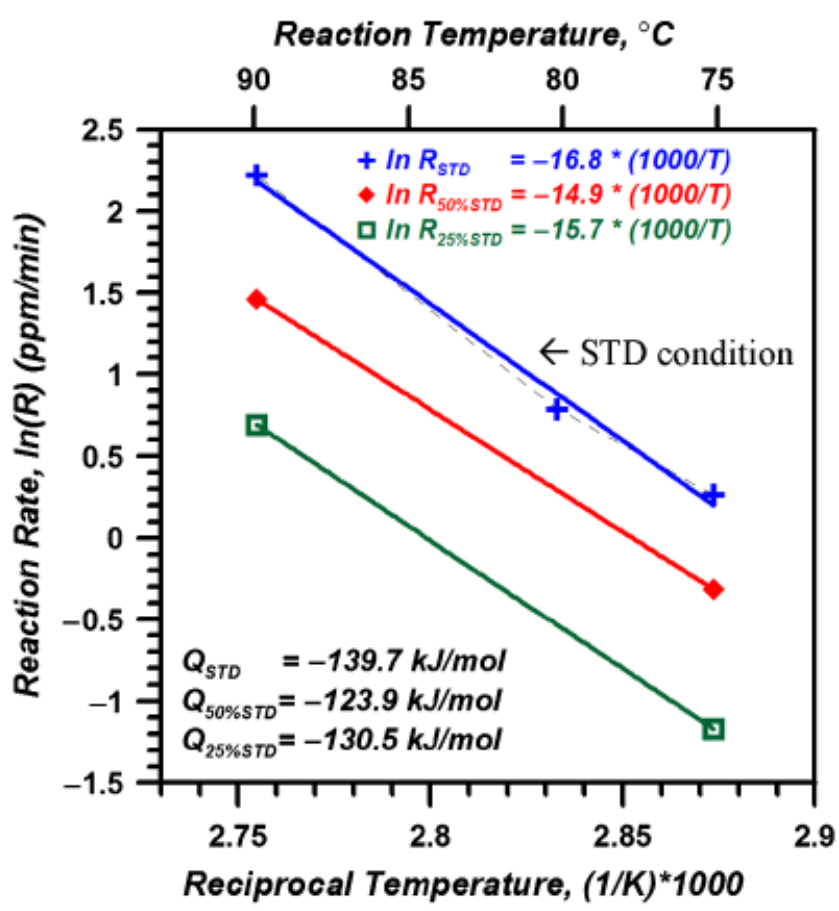

Fig. 7. Arrhenius plots of reaction rates versus the reciprocal absolute temperature for three cases. The activation energies for these three cases are $-139.7,-123.9$, and $-130 \mathrm{~kJ} / \mathrm{mol}$, respectively. 

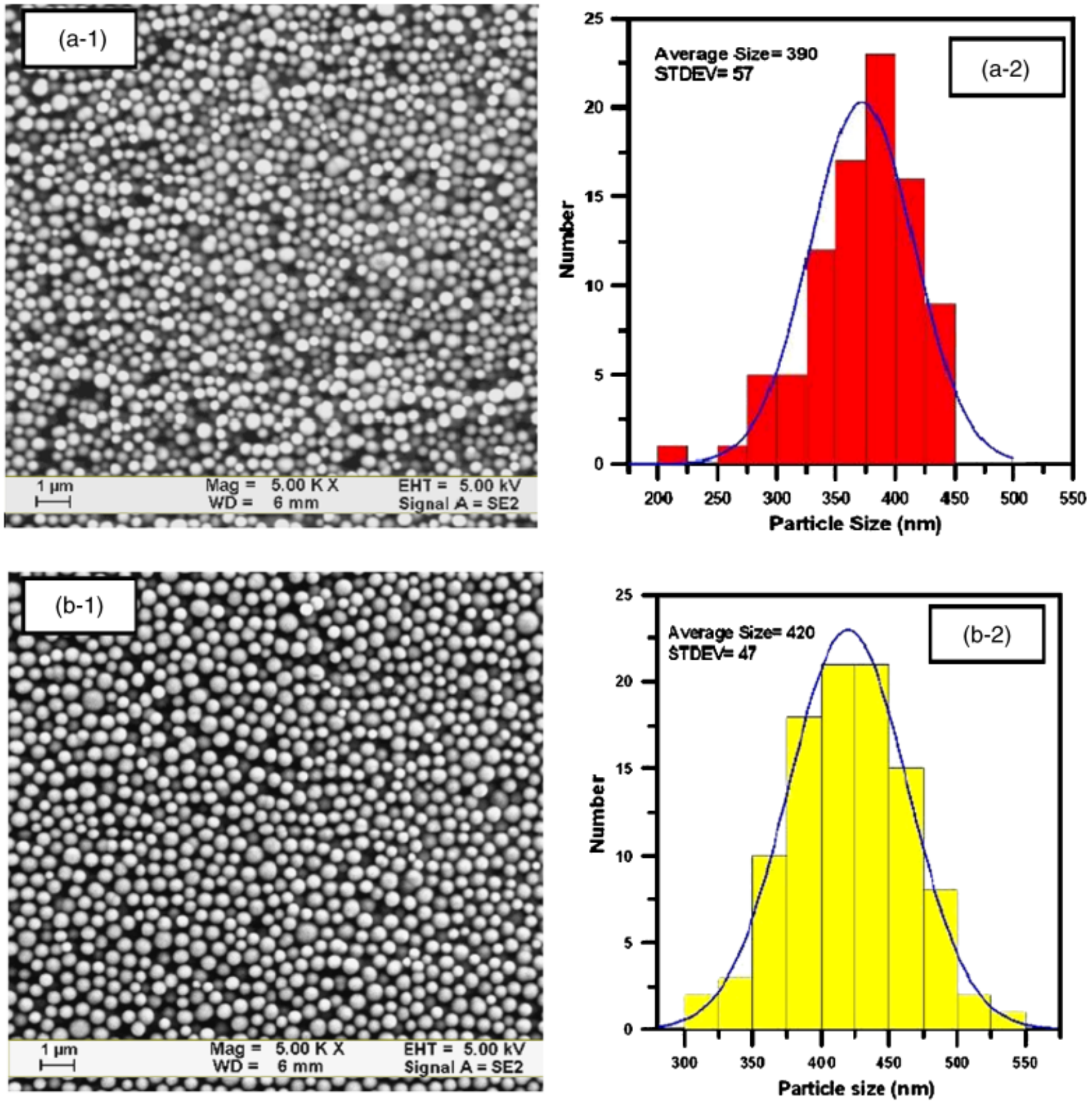

Fig. 8. Scanning electron microscopic micrographs revealing the size distributions of D-3 with different aging periods, (a) $5 \mathrm{~h}$ and (b) $16 \mathrm{~h}$, and their size distributions.

Especially for sample A-1, the amount of CA is too small to result in individual spherical particles. A similar result can also be observed in sample B-1 aged at $80^{\circ} \mathrm{C}$. Further, the linear relationship between particle size and concentration of CA can be obtained for A- and B-series (Figs. 2 and 4), meaning the reaction mechanism for both series are analogous. ICP results for the B-series, i.e., B-0, B-2, and B-4 (Fig. 6), can prove that adding $\mathrm{CA}$ would not speed up the reaction rate with or without $\mathrm{CA}$ addition. Therefore, the correlation of size and amount of $\mathrm{CA}$ can be explained with respect to nucleation. For cases B-2 and B-4 $\left(80^{\circ} \mathrm{C} / 7 \mathrm{~h}\right)$, the particle size is about 100 and $420 \mathrm{~nm}$, respectively. After $7 \mathrm{~h}$ of reaction, the residual $\left[\mathrm{In}^{3+}\right]$ is about 1200 and 1500 ppm for cases B-2 and B-4, respectively. The volume of a sphere is proportional to $r^{3}$. Therefore, the volume ratio for cases B-2 and B-4 is $1: 4.2^{3}=1: 74$. It is assumed that all the particles have the same density, as a result of which the nuclei number ratio between cases B-2 and B-4 can be calculated as 100:1. Therefore, adding CA could reduce the formation of nuclei in the solution.

In our previous study, ${ }^{22}$ we proved that the consumption rates of $\left[\mathrm{In}^{3+}\right]$ revealed the precipitation kinetics of In-precipitate

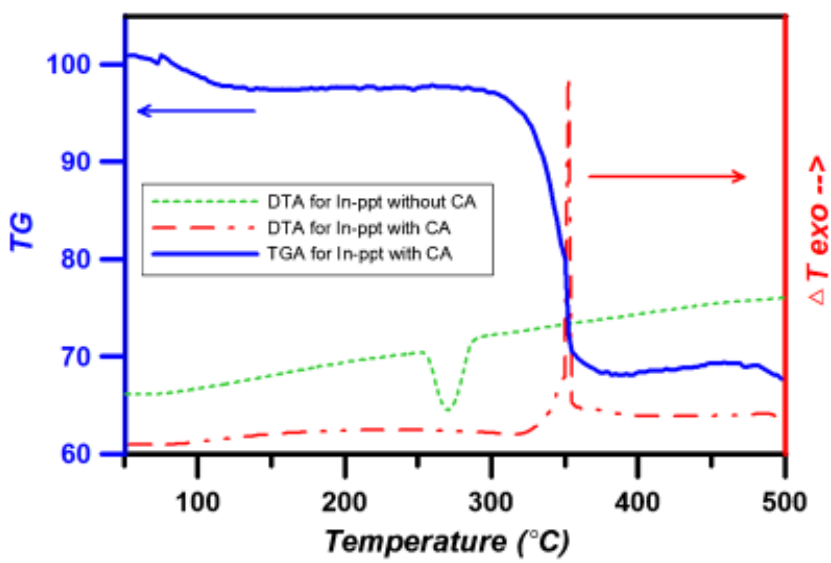

Fig. 9. Thermogravimetric analysis (TGA) and differential thermal analysis (DTA) analysis for sample D-3 aged for $16 \mathrm{~h}$. DA analysis for B-0 (without citric acid addition) was also done for comparison. The mass of In-precipitate (In-ppt) for TA was about $8 \mathrm{mg}$. Analysis range is from room temperature to $500^{\circ} \mathrm{C}$ with a heating rate of $5^{\circ} \mathrm{C} / \mathrm{min}$. 


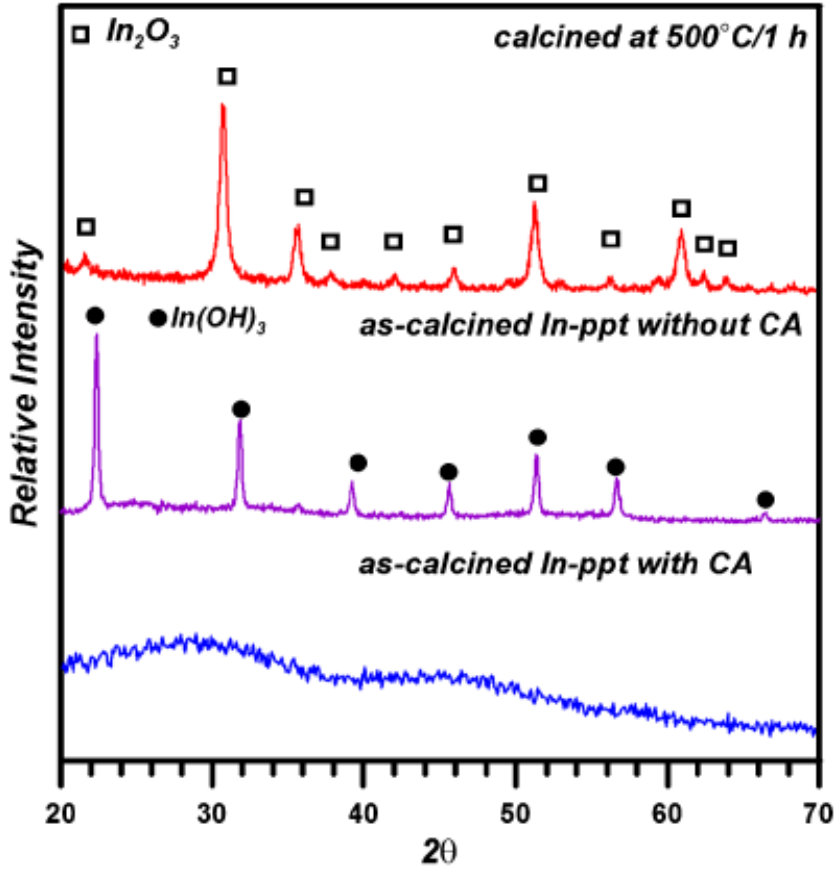

Fig. 10. X-ray diffraction patterns for sample D-3 aged for $16 \mathrm{~h}$ (ascalcined In-ppt with citric acid (CA)) and B-0 (without adding CA), and sample D-3 after $500^{\circ} \mathrm{C} / \mathrm{h}$ of calcination.

to be a zero-order reaction with time at $65^{\circ}-85^{\circ} \mathrm{C}$ without $\mathrm{CA}$ addition. In other words, the precipitation reaction was urea decomposition controlled. The same result can be obtained in the system with CA addition, as shown in Fig. 5. By generalizing the results from Fig. 5, the reaction rate constant $k$ for $\mathrm{C}$ - and D-series can be plotted. Figure 13 shows the relationship between the reaction rates and the concentration percentage of STD for C- and D-series. $k_{90}\left(=96 \times 10^{-3}\right)$ is the rate constant for $\mathrm{C}$-series aged at $90^{\circ} \mathrm{C}$ and $k_{75}\left(=14 \times 10^{-3}\right)$ is for D-series

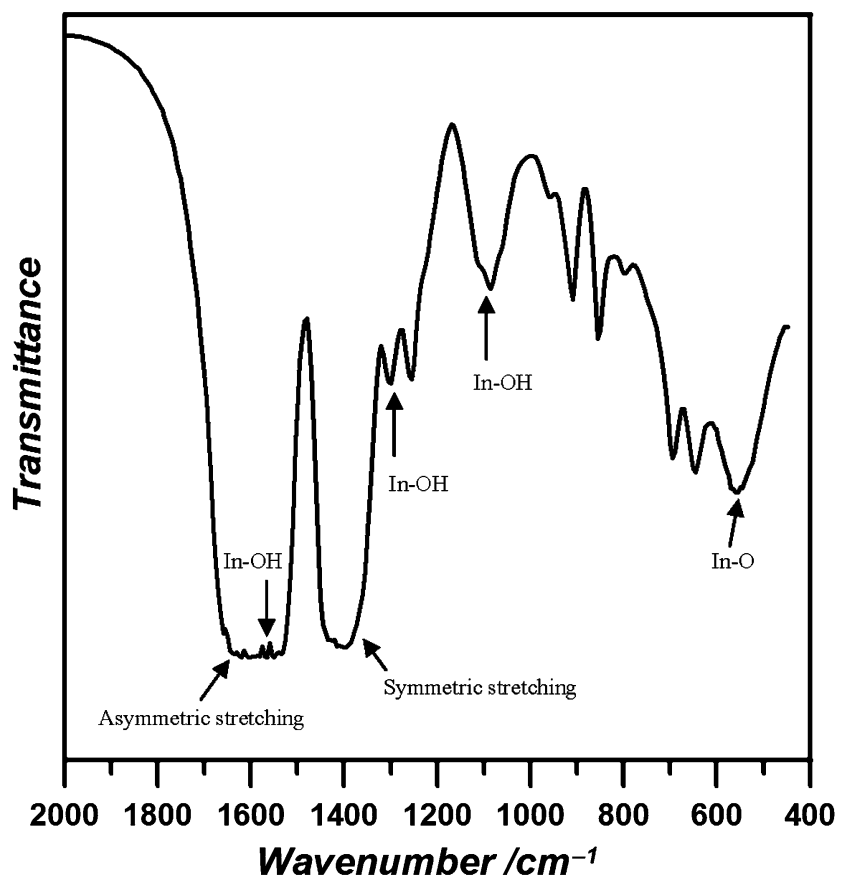

Fig. 11. Fourier transform infrared analysis of sample D-3 (aged for $16 \mathrm{~h}$ ). The sample was dried at $80^{\circ} \mathrm{C}$ for 3 days. The carboxylate anion resulted in absorption peaks at $1550-1650$ and $1400 \mathrm{~cm}^{-1}$ for strong asymmetric stretching and weak symmetric stretching, respectively. ${ }^{25}$ Some In-OH or In-O bands can also be seen in the literature. ${ }^{26}$
Table III. Experimental Conditions for the Addition of Different $\alpha$-Hydroxyl Acids (AHAs)

\begin{tabular}{|c|c|c|c|c|c|c|c|}
\hline \multirow[b]{2}{*}{ Number } & \multicolumn{5}{|c|}{ Concentration $(M)$} & \multirow[b]{2}{*}{$\begin{array}{l}\text { Aging } \\
\text { period } \\
\text { (h) }\end{array}$} & \multirow[b]{2}{*}{ Notes } \\
\hline & $\operatorname{In}^{3+}$ & $\begin{array}{c}\text { Citric } \\
\text { acid } \\
\mathrm{C}_{6} \mathrm{H}_{8} \mathrm{O}_{7}\end{array}$ & $\begin{array}{c}\text { Tartaric } \\
\text { acid } \\
\mathrm{C}_{4} \mathrm{H}_{6} \mathrm{O}_{5}\end{array}$ & $\begin{array}{c}\text { Malic } \\
\text { acid } \\
\mathrm{C}_{4} \mathrm{H}_{6} \mathrm{O}_{6}\end{array}$ & $\begin{array}{c}\text { Urea } \\
\mathrm{CH}_{4} \mathrm{~N}_{2} \mathrm{O}\end{array}$ & & \\
\hline E-1 & 0.8 & 0.1 & $\mathrm{X}$ & $X$ & 1.2 & $6-24$ & $\begin{array}{l}\text { No } \\
\text { precipitate }\end{array}$ \\
\hline E-2 & 0.8 & 0.5 & $X$ & $X$ & 1.2 & $6-24$ & \\
\hline E-3 & 0.8 & 1.0 & $\mathrm{X}$ & $\mathrm{X}$ & 1.2 & $6-24$ & $\begin{array}{l}\text { Agglomera- } \\
\text { tion }\end{array}$ \\
\hline F-1 & 0.8 & $\mathrm{X}$ & 0.1 & $\mathrm{X}$ & 1.2 & $6-24$ & \\
\hline $\mathrm{F}-2$ & 0.8 & $\mathrm{X}$ & 0.5 & $X$ & 1.2 & $6-24$ & \\
\hline $\mathrm{F}-3$ & 0.8 & $\mathrm{X}$ & 1.0 & $\mathrm{X}$ & 1.2 & $6-24$ & \\
\hline G-1 & 0.8 & $X$ & $X$ & 0.1 & 1.2 & $6-24$ & \\
\hline G-2 & 0.8 & $X$ & $X$ & 0.5 & 1.2 & $6-24$ & \\
\hline G-3 & 0.8 & $\mathrm{X}$ & $\mathrm{X}$ & 1.0 & 1.2 & $6-24$ & $\begin{array}{l}\text { Agglomera- } \\
\text { tion }\end{array}$ \\
\hline
\end{tabular}

The unit of the concentration is $10^{-2} \mathrm{~mol} / \mathrm{kg}$.

aged at $75^{\circ} \mathrm{C}$. For both cases, the linear relationship behavior related to the concentration. From this figure, the effect of temperature for reaction rate could be fully expressed.

Several studies serve as comparison cases corresponding to the synthesis processes with urea reacted at different temperatures. Figure 14 shows the Arrhenius plots of reaction rates for several cases. The activation energies for $Q_{1}, Q_{2}$, and $Q_{3}$ are the decomposition of pure urea, ${ }^{27}$ the precipitation of $\mathrm{Tb}^{3+}$-doped $\mathrm{Y}(\mathrm{OH}) \mathrm{CO}_{3} \cdot \mathrm{H}_{2} \mathrm{O}$ with the addition of urea, ${ }^{6}$ and the precipitation of $\operatorname{In}(\mathrm{OH})_{3}$ with urea, respectively. $Q_{4}$ is the result calculated from Fig. 13 in this work. The activation energies for $Q_{2}$, $Q_{3}$, and $Q_{4}$ are 137,128 , and $137 \mathrm{~kJ} / \mathrm{mol}$, respectively. The result of $Q_{4}$ agrees with the references, implying that the mechanism of reaction in this study is the decomposition of urea.

DTA results (Fig. 9) show an endothermic peak of sample B-0 (without CA addition), indicating the phase transformation of $\mathrm{In}(\mathrm{OH})_{3}$ to $\mathrm{In}_{2} \mathrm{O}_{3}$. However, an exothermic peak (at about $350^{\circ} \mathrm{C}$ ) of the sample by $\mathrm{CA}$ addition can be observed in sample $\mathrm{D}-3$. It is commonly understood that if the precipitate of D-3 is hydrous, the decomposition of $\mathrm{OH}$ bonds would result in an endothermic peak rather than an exothermic peak. As a result, we are sure the spherical In-precipitate is a kind of In complex compound, and the combustion of the compound undergoes heat release and transforms to the $\mathrm{In}_{2} \mathrm{O}_{3}$ phase. TA-mass result shows a gas with an atomic number of 44, i.e., $\mathrm{CO}_{2}$ would release from the sample when heated higher than $350^{\circ} \mathrm{C}$. The FTIR result (Fig. 11) shows that carboxylate anion can be detected in the powder. The combustion of the carboxylate anion would result in an exothermic reaction releasing $\mathrm{CO}_{2}$ gas. The violent carboxylate anion burnout would result in the porous structure or hollow core of powder, as shown in TEM crosssection images (Fig. 3).

From the results described above, there are two parameters that need to be monitored. First, adding CA could affect the nucleation and growth behavior of the In-precipitate. Without CA addition, single crystalline particles of oval or stick-like structures were formed. The longitudinal direction of the precipitate was $\langle 110\rangle .^{22}$ However, in the presence of $\mathrm{CA}$, the growth rates in all directions are the same; thus, the reaction results in spherical precipitates with an amorphous state.

Second, when the addition of CA is inadequate, no Inprecipitate could be obtained or the In-precipitate would be too small to be observed unless aged for longer than $24 \mathrm{~h}$ at temperatures $>80^{\circ} \mathrm{C}$. Additionally, instead of spherical particles, clustering In-precipitates would be obtained. Again, with an increase in the CA concentration, the particle size increases accordingly.

When assembling the PBG crystal, it is necessary to examine the size distribution of the particles used. The coefficient of 


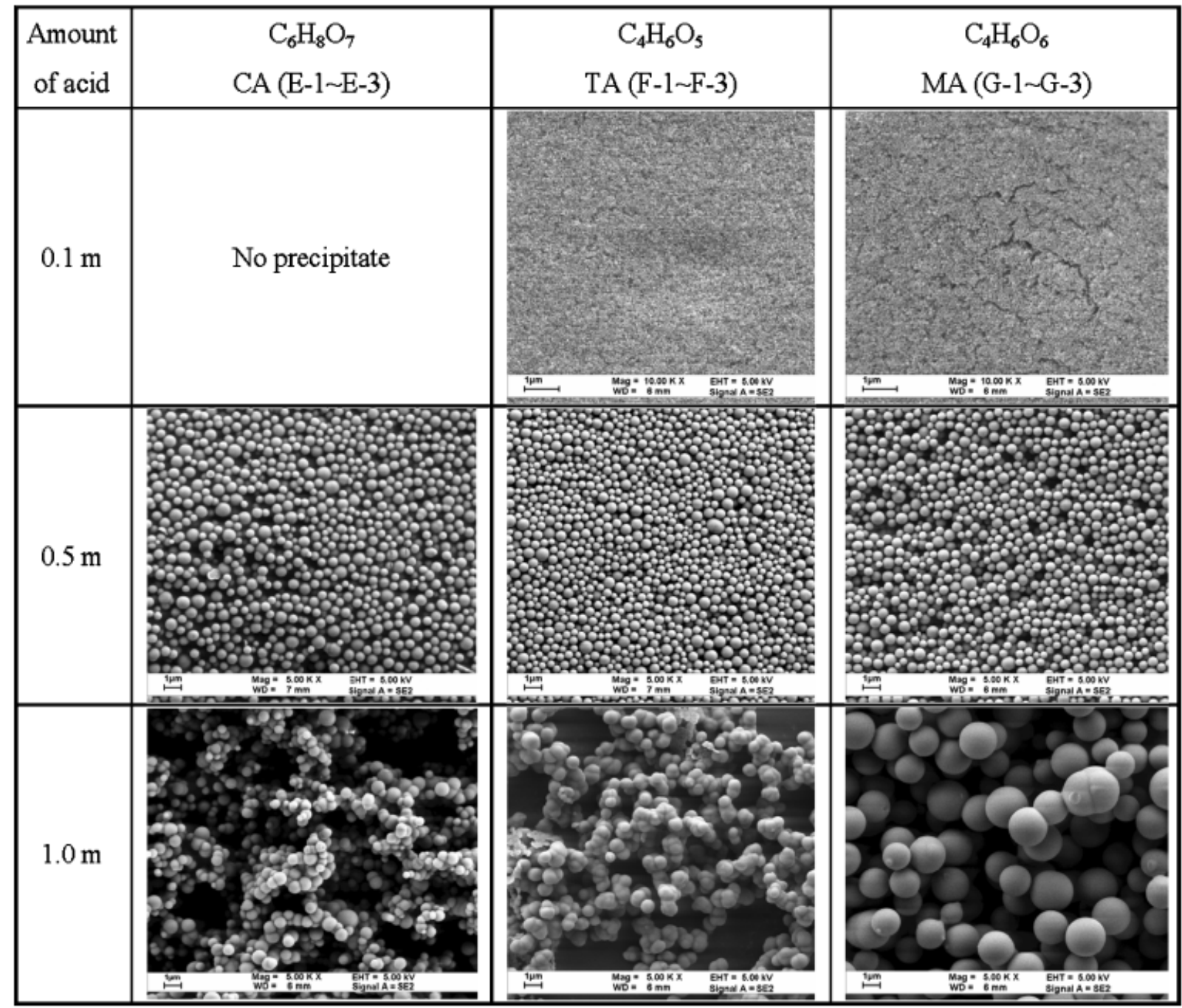

Fig. 12. Morphologies of In-precipitate with different $\alpha$-hydroxyl acid additions, and concentrations aged at $80^{\circ} \mathrm{C}$ for $6 \mathrm{~h}$. The unit of the concentration is $10^{-2} \mathrm{~m}$.

variation or polydispersity, $C_{\mathrm{v}}$, is usually adopted to represent the degree of size distribution. ${ }^{28}$

$$
\begin{aligned}
d_{\mathrm{ave}} & =\frac{\sum n_{i} d_{i}}{\sum n_{i}} \\
C_{\mathrm{v}} & =\frac{\left\{\sum\left(d_{i}-d_{\mathrm{ave}}\right)^{2} / \sum n_{i}\right\}^{1 / 2}}{d_{\mathrm{ave}}}
\end{aligned}
$$

$C_{\mathrm{v}}$ values of E-2, F-2, and G-2 are close to $20 \%$. As a result, two criteria of particle synthesis should be followed to obtain mono-dispersive particles. First, the precipitation should take a longer aging period and allow particles to undergo the ripening step, so that particles can grow uniformly. This is one method to reduce the polydispersity. The results of D-3 samples represent evidence showing the polydispersity decreasing from $15 \%$ to $11 \%$ when the aged time increased from 5 to $16 \mathrm{~h}$. The second point is about the $\mathrm{pH}$ value for the whole precipitation procedure, including nucleation, growth, and ripening. The acidity should be lower than the IEP. Otherwise, particle agglomeration would occur and possibly form dumbbell-like particles. Once the initial urea concentration is too high, the decomposition of urea releases too much $\mathrm{OH}^{-}$ion and increases the $\mathrm{pH}$ value of the solution. This explains why the longer the aging time, the harder the agglomeration state, as seen in many cases with higher urea concentration.

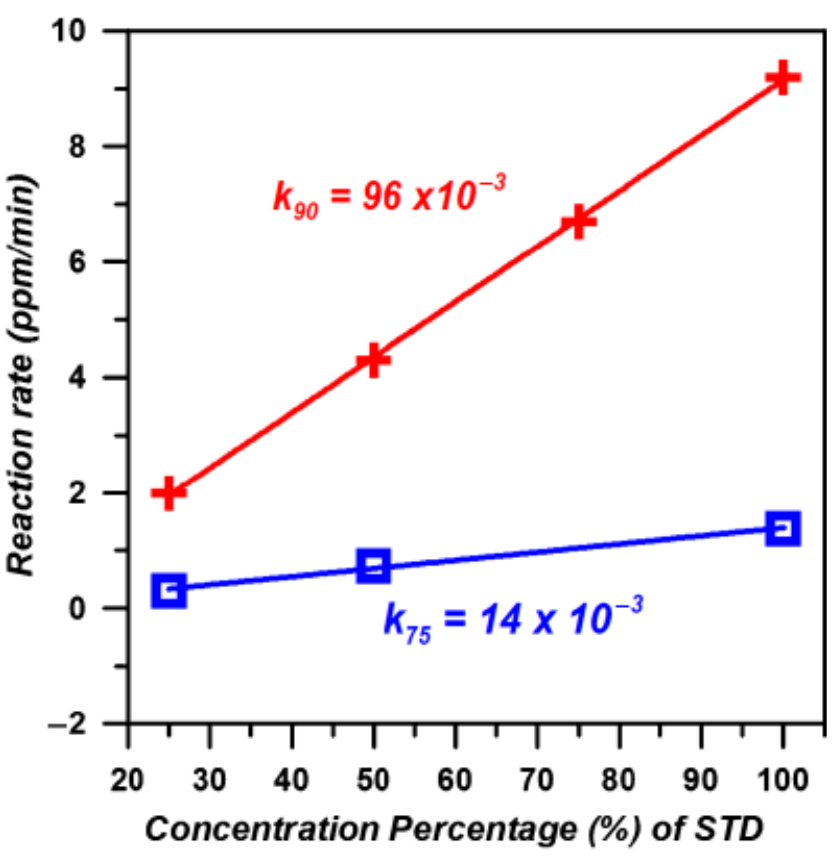

Fig. 13. Relationship between reaction rates and the concentration percentage of standard. $k_{90}$ is the rate constant for $\mathrm{C}$-series aged at $90^{\circ} \mathrm{C}\left(96 \times 10^{-3}\right)$ and $k_{75}$ is the rate constant for D-series aged at $75^{\circ} \mathrm{C}$ $\left(14 \times 10^{-3}\right)$. 


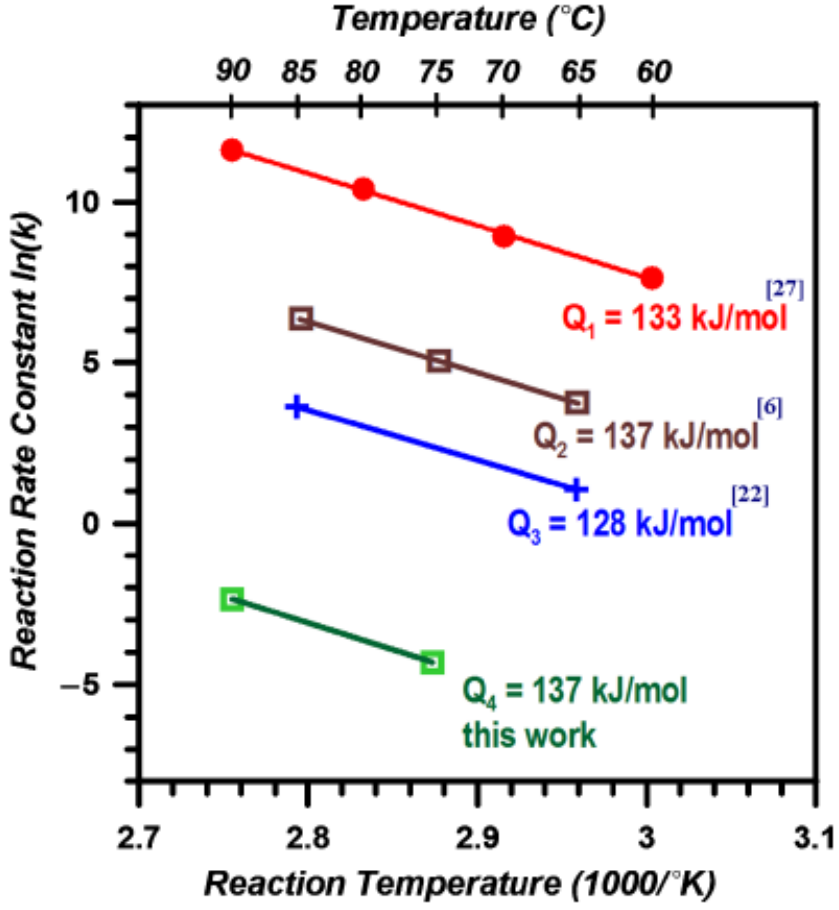

Fig. 14. Arrhenius plots of reaction rates versus the reciprocal Kelvin temperature for four cases. A description of $Q_{1}, Q_{2}, Q_{3}$, and $Q_{4}$ is seen in the text.

\section{Conclusions}

In this study we have demonstrated how to synthesize spherical particles using the homogeneous precipitation method with the addition of CA, TA, or MA. The chemicals are all carboxyl acids and possess similar functions. The reaction rate in this study is controlled by the amount of urea, while the nucleation mechanism is affected by the quantity of CA. A similar trend can also be found in the MA and TA system. To obtain particles with a low polydispersity, good control of the concentration of urea and keeping the $\mathrm{pH}$ value of the solution always far from the IEP point are two important factors that can prevent agglomeration. A longer aging time results in a uniform particle size because of the final stage of particle growth by ripening, and the resulting mono-dispersed state.

\section{References}

${ }^{1}$ E. Matijević, "Uniform Inorganic Colloid Dispersions. Achievements and Challenges," Langmuir, 10, 8-16 (1994).

${ }^{2}$ E. Matijevi, "Monodispersed Colloids: Art and Science," Langmuir, 2, 12-20 (1986)

${ }^{3}$ E. Matijevi, "Preparation and Properties of Uniform Size Colloids," Chem. Mater., 5, 412-26 (1993).

${ }^{4} \mathrm{~W}$. Stöber and E. Bohn, "Controlled Growth of Monodispersed Silica Spheres in the Micron Size Range," J. Colloid Interface Sci., 26, 62-9 (1986).
${ }^{5}$ T. W. Chen and W. C. J. Wei, "Fabrication and Characterization of Silica Photonic Bandgap Crystal"; Master Thesis, National Taiwan University, MSE, Taiwan, 2002 .

${ }^{6}$ J. M. Sung, S. E. Lin, and W. C. J. Wei, "Synthesis and Reaction Kinetics for Monodispersive $\mathrm{Y}_{2} \mathrm{O}_{3}: \mathrm{Tb}^{3+}$ Spherical Phosphor Particles," J. Eur. Ceram. Soc., 27, 2605-11 (2007)

${ }^{7}$ B. Djuričić, S. Pickering, D. McGarry, P. Glaude, P. Tambuyser, and K. Schuster, "The Properties of Zirconia Powders Produced by Homogeneous Precipitation," Ceram. Int., 21, 195-206 (1995).

${ }^{8}$ E. W. Seelig, B. Tang, A. Yamilov, H. Cao, and R. P. H. Chang, "SelfAssembled 3D Photonic Crystals from ZnO Colloidal Spheres," Mater. Chem. Phvs., 80, 257-63 (2003).

${ }^{9}$ M. Keshmiri and T. Troczynski, "Synthesis of Narrow Size Distribution SubMicron $\mathrm{TiO}_{2}$ Spheres," J Non-Cryst. Solids, 311, 89-92 (2002).

${ }^{10} \mathrm{X}$. Jiang, T. Herricks, and Y. Xia, "Monodispersed Spherical Colloids of Titania: Synthesis, Characterization, and Crystallization," Adv. Mater., 15 [14] 1205-9 (2003).

${ }^{11}$ Y. Zhao, Z. Zhang, Z. Wu, and H. Dang, "Synthesis and Characterization of Single-Crystalline $\mathrm{In}_{2} \mathrm{O}_{3}$ Nanocrystals Via Solution Dispersion," Langmuir, 20, 27-9 (2004).

${ }^{12}$ K. Soulantica, S. Erades, F. Senocq, A. Maisonnat, and B. Chaudret, "Synthesis of Indium and Indium Oxide Nanoparticles from Indium Cyclopentadienyl Precursor and Their Application for Gas Sensing," Adv. Funct. Mater., 13 [7] 553-7 (2003).

${ }^{13}$ A. Gurlo, N. Barsan, U. Weimar, M. Ivanovskaya, A. Taurino, and P. Siciliano, "Polycrystalline Well-Shaped Blocks of Indium Oxide Obtained by the Sol-Gel Method and Their Gas-Sensing Properties," Chem. Mater., 15, 4377-84 (2003).

${ }^{14} \mathrm{C}$. Li, D. Zhang, X. Liu, S. Han, T. Tang, and J. Han, " $\mathrm{In}_{2} \mathrm{O}_{3}$ Nanowires as Chemical Sensors," Appl. Phy. Lett., 82 [10] 1613-5 (2003).

${ }^{15} \mathrm{Z}$. Zhan, D. Jiang, and J. Xu, "Investigation of a New $\mathrm{In}_{2} \mathrm{O}_{3}$-Based Selective $\mathrm{H}_{2}$ Gas Sensor with Low Power Consumption," Mater. Chem. Phys., 90, 250-4 (2005)

${ }^{16}$ K. Yura, K. C. Fredrikson, and E. Matijevic, "Preparation and Properties of Uniform Colloidal Indium Compounds of Different Morphologies," Colloids Surf., 50, 281-93 (1990).

${ }^{17}$ L. A. Perez-Maqueda, L. Wang, and E. Matijevi, "Nanosized Indium Hydroxide by Peptization of Colloidal Precipitates," Langmuir, 14, 4397-401 (1998)

${ }^{18}$ D. Yu, S. H. Yu, S. Zhang, J. Zuo, D. Wang, and Y. Qian, "Metastable Hexagonal $\mathrm{In}_{2} \mathrm{O}_{3}$ Nanofibers Templated from InOOH Nanofibers Under Ambient Pressure," Adv. Funct. Mater., 13 [6] 497-501 (2003).

${ }^{19}$ D. Zhang, C. Li, X. Liu, S. Han, T. Tang, and C. Zhou, "Doping Dependent $\mathrm{NH}_{3}$ Sensing of Indium Oxide Nanowires," Appl. Phys. Lett., 83 No. 9 [1] 1845-7 (2003).

${ }^{20} \mathrm{~S}$. Avivi, Y. Mastai, and A. Gedanken, "Sonohydrolysis of $\mathrm{In}^{3+}$ ions: Formation of Needlelike Particles of Indium Hydroxide," Chem. Mater., 12, 1229-33 (2000).

${ }^{21}$ Y. Zhao, Z. Zhang, Z. Wu, and H. Dang, "Synthesis and Characterization of Single-Crystalline $\operatorname{In}_{2} \mathrm{O}_{3}$ Nanocrystals Via Solution Dispersion," Langmuir [20] 27-9 (2004).

${ }^{22}$ S. E. Lin and W. C. J. Wei, "Synthesis and Growth Kinetics of Monodispersive Indium Hydrate Particles," J. Am. Ceram. Soc., 89 [2] 527-33 (2006).

${ }^{23}$ S. E. Lin and W. C. J. Wei, "Synthesis and Characterization of Monodispersive $\mathrm{In}_{2} \mathrm{O}_{3}$ Particles," Key Eng. Mater. 280-3, 499-504 (2005).

${ }^{24}$ S. Hamada, Y. Kudo, and T. Kobayashi, "Precipitation of Uniform Indium Hydroxide Particles from Indium 2-Aminobutyrato Complex Solutions," Colloids Surf. A: Physicochem. Eng. Asp., 79, 227-32 (1993).

${ }^{25} \mathrm{H}$. Taguchi, S. I. Matsu-ura, and M. Nagao, "Synthesis of $\mathrm{LaMnO}_{3+\delta}$ by Firing Gels Using Citric Acid," J. Solid State Chem., 129, 60-5 (1997).

${ }^{26} \mathrm{~W}$. H. Ho and S. K. Yen, "Preparation and Characterization of Indium Oxide Film by Electrochemical Deposition," Thin Solid Films, 498, 80-4 (2006)

${ }^{27}$ W. H. R. Shaw and J. J. Bordeaux " "The Decomposition of Urea in Aqueous Media," J. Chem. Soc., 77, 4729-33 (1955).

${ }^{28}$ D. Nagao, T. Satoh, and M. Konno, "A Generalized Model for Describing Particle Formation in the Synthesis of Monodispersed Oxide Particles Based on the Hydrolysis and Condensation of Tetraethyl Orthosilicate," J. Colloid Interface Sci., 232, 102-10 (2000). 